\title{
Mal-estar na literatura brasileira contemporânea
}

CHRISTIAN INGO LENZ DUNKER ${ }^{I}$

\section{Mal-estar, sofrimento e sintoma}

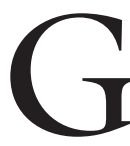
OSTARIA de apresentar aqui uma articulação comparativa entre as noções de metáfora do sintoma, narrativa de sofrimento e mal-estar na nomeação, empregando para isso quatro movimentos da literatura brasileira contemporânea. Trata-se de replicar, em escala reduzida, o que propus em meu livro Mal-estar, sofrimento e sintoma (Dunker, 2015) valendo-me do Cinema da Retomada. Naquela ocasião levantei como nosso cinema tentou, de certa maneira, voltar ao hiato de reflexão sobre o Brasil, trazido pelo regime civil-militar, de 1964-1985, reinterpretando manifestações estéticas que lhe precederam como o Cinema Novo e o Cinema Marginal, a poesia concreta e o neoconcretismo, ou que lhe foram contemporâneos, como a Tropicália (1967-1968). O Cinema da Retomada organiza-se em torno da fratura da transmissão cultural brasileira e de alguns traços característicos: a ascensão da narrativa da vingança, a temática da criança como último ideal, o descompasso como lógica temporal do encontro e os cenários fechados em prisões, favelas e condomínios como modalidades de preferenciais de territorialização simbólica do espaço. Acresce dizer que a Retomada é também uma resposta ao início das experiências neoliberais brasileiras, tanto do ponto de vista do deslocamento do lugar do sofrimento na experiência social, que deixa se ser um obstáculo e passa a ser meio de incremento do processo produtivo, quanto do ponto de vista hibridização de tecnologias e de estratégias fílmicas entre o cinema e a publicidade.

Segundo a tese aqui apresentada, uma narrativa de sofrimento é composta por pelo menos duas séries transformativas que circundam uma experiência de mal-estar. Por exemplo, em Cidade de Deus (2002), para alguns o último filme do ciclo inicial da Retomada, temos uma série composta pela transformação subjetiva do pequeno fotógrafo negro que começa a retratar sua própria comunidade com um olhar jornalístico e outra série transformativa marcada na trajetória de Zé Pequeno, em sua ascensão como traficante de drogas. As duas séries, uma baseada na necessidade de reconfigurar um pacto social e a outra em torno da apropriação de um objeto intrusivo, tentam nomear por meio de um cruzamento ordenado de perspectivas o mal-estar na favela carioca da Cidade de Deus. A metáfora da violência mostrada e da violência praticada constitui assim uma estratégia de formalização do sintoma. 


\section{A Verdade e o Real}

Narrativizar experiências de sofrimento envolve criar certa unidade transformativa, inscrevendo-a em uma razão diagnóstica, discernindo causas e efeitos, nexos de implicação e disjunção. Narrativas de sofrimento não são apenas versões do discurso psiquiátrico, do código psicológico ou da semântica psicanalítica, mas a maneira como sintomas são discursivamente tramitados em termos de laços sociais. Narrativas de sofrimento organizam-se em dois grandes gêneros, quer se orientem para a determinação, quer para a indeterminação, que se dediquem a afirmação ou negação de relações de gênese ou causa. Sigo aqui a tese lacaniana de que "a verdade tem estrutura de ficção" (Lacan, 1955, p.253). Isso significa que a experiência mesma do sofrimento é transformada pelos seus modos de representação, de compartilhamento ou de apresentação. Esse aspecto autoperformativo, autorrealizador ou autopoiético do sofrimento explica sua afinidade com a noção de transferência, como produção de um sujeito que é suposto, portanto hipotético ou ficcional, e que se desenrola em torno de um saber, seja ele inconsciente, seja ele narrativo.

Como procuramos mostrar em outro contexto, a semiologia psicanalítica é reiteradamente dependente da narrativa literária (Dunker, 2012). Expressa por uma solidariedade discursiva, entre demanda, transferência e identificação, o sofrimento tornou-se parâmetro central para a literatura contemporânea, em acordo com o que Deleuze, com Kafka, chama de Literatura Menor. Se as gramáticas de determinação subordinam o sofrimento ao ponto de vista que as descreve, a literatura emergente a partir dos anos 1985 procura mostrar que o sofrimento não se subordina à voz que o enuncia. Isso ocorre em relação aos três quesitos fundamentais da literatura menor: "a desterritorialização da língua, a ligação individual no imediato político, o agenciamento coletivo da enunciação" (Deleuze; Guatarri, 2014, p.39). Nossa pesquisa deteve-se nas inflexões literárias em torno das narrativas de sofrimento, uma vez que isso permite entender o giro nos modos de sofrimento dos pacientes em psicanálise, notadamente a partir da virada do século.

Desterritorialização da língua é o que se pode chamar, em psicanálise, de transferência (Übertragung). A ligação política imediata é certamente o campo formado pela demanda, ao passo que o coletivo de uma enunciação constitui a variedade de configurações entre massa, classe e grupo, examinada por Freud, em Psicologia de massas e análise do eu, e seu tema fundamental que é a identificação.

Compreender a mutação de nossas experiências de sofrimento significa reconstruir a patologia de seu próprio reconhecimento, por exemplo, o bloqueio de sua expressão, a hiperdeterminação de sua causalidade, a indeterminação ou determinação moral de sua natureza, seu caráter individualizante ou coletivizante, a alienação ou desconhecimento de suas determinações desejantes. Por isso podemos falar em uma ontologia social do sofrimento. $\mathrm{O}$ sofrimento possui, 
portanto, estrutura de ficção e efeitos no real. O sofrimento socialmente esperado para certa configuração social é também a maneira como contradições sociais se articulam com formas expressivas, notadamente de natureza estética.

O traço particular da literatura brasileira, para o qual quero chamar a atenção no arco histórico em questão, aborda o sofrimento a partir de uma espécie de recuo de suas pretensões de nomeação. Enquanto o Cinema da Retomada esforça-se por nomear o mal-estar à brasileira, como um problema de descontinuidade histórica e visibilização da violência, a literatura parece ter se concentrado na desarticulação política de sua demanda, no esgotamento das formas de reinvindicação e da insuficiência da forma romance para dar conta de certas experiências transformativas de sofrimento. Enquanto as estruturas narrativas do cinema tendem a problematizar as relações entre a verdade e o real, explorando o literal entre documentário e a ficção, a estratégia literária e das artes visuais concentrou-se nas modalidades de perda da experiência. Ao contrário do cinema, a literatura parece ter se dedicado a problemas como a corrupção da forma comunicacional, a desestabilização do narrador e da sintaxe proposicional, a emergência da VOz como índice de desapossamento da experiência. Enquanto o cinema abordou os paradoxos da propriedade e da possessão, a literatura interessou-se pelas experiências de dissolução da identidade e do desapossamento de si. A intrusão biográfica, testemunhal ou autoral não se apresenta aqui como um recurso expressivo de uma subjetividade contida, mas como estratégia para uma poética da indeterminação e da perda da unidade.

Lembremos que o real, na acepção proposta por Lacan, não tem estrutura de ficção. O Real não se diz por movimentos de exposição e retroação, nem se deduz dos lugares da enunciação e do discurso. O Real não é suscetível a bloqueios de reconhecimento, porque ele é falha que se repete, voltando sempre ao mesmo lugar como hiância no interior de uma série. O real é crise, impossibilidade ou resistência de nomeação, ou melhor, nomeação que não cessa de não se escrever. Ele aparece em algum ponto no qual as relações, genericamente duais, entre corpo e linguagem se desequilibram. As estruturas de ficção de um lado e as estratégias de nomeação, de outro, formam uma determinada relação entre Verdade e Real. Na literatura isso aparece como um jogo de forças entre linguagem e corpo, que se traduz em temas recorrentes como a morte, a voz e a materialidade da carne.

Ora, um dos modelos freudianos mais bem-sucedidos para pensar essa relação entre a verdade e o real é o modelo do luto. Nele a perda real engendra um trabalho de pesquisa sobre a verdade do objeto perdido. Esse trabalho é chamado de luto. Quando o real da perda é contornado por processo de identificação, demanda e transferência, o objeto é finalmente introjetado, segundo a imagem fundamental dos filhos que devoram seu pai, erigindo dentro de si a lei.

Contudo, o modelo freudiano apresenta problemas e limites. O principal deles é pensar que o trabalho de luto é sempre um processo de apropriação, de 
ganho, de possessão, de enriquecimento, daí ele ter sido usado para pensar processos de formação cultural, de acordo com a proposta modernista. Clinicamente sabemos que há algum problema nesse modelo, principalmente quando se considera processo de luto cujo ponto crucial não é a incorporação, a aceitação e a ingestão do objeto perdido, mas o ato de dissolução do próprio eu, na medida em que ele se alterna com o objeto, no perspectivismo que determina a gramática do luto. Há lutos que não precisam ser melancólicos para que a sombra do objeto dissolva o eu, em uma catharse que não é integrativa, mas desintegrativa. Esse problema tem nos levado a trazer o perspectivismo ameríndio descrito pelo antropólogo brasileiro Eduardo Viveiros de Castro para a psicanálise e para a literatura. Como coloca Roberto Zular (2014, p.28):

No ponto de inflexão da perspectiva como um ponto a ser ocupado (uma posição sujeito) e como um ponto de vista produzido pelo corpo e pelos diferentes corpos, a morte se torna o lugar mesmo da indiferência, podendo ser pensada como a possibilidade de variação dos pontos de vista, assim como o luto torna-se uma produção de mundo que sucede este "quase acontecimento".

\section{O retorno das vanguardas e o hiato da brasilidade (1930-1960)}

Em muitos países a adoção de ideias e práticas neoliberais emanou de uma percepção social de instabilidade, desemprego ou anomia. Foi nesse contexto que Pinochet testou as ideias da Escola de Chicago logo após o golpe de 1973, que Margareth Tatcher e Ronald Regan deram curso a uma retirada do Estado em relação à economia. $\mathrm{O}$ Brasil parece constituir uma exceção a essa regra, $\mathrm{o}$ que permite supor que o neoliberalismo tem uma implantação tardia, que é contemporânea dos tempos de abertura e reversão das políticas liberais promovidas pelos governos militares. Nos importa pensar o neoliberalismo como um discurso capaz de agenciar diferentes narrativas de sofrimento de uma nova maneira, não mais como obstáculo ã produção, mas como incorporação do sofrimento como força produtiva. Essa é a ideia-chave na noção de "capital humano", por exemplo. A concomitância entre a introdução das práticas neoliberais e a abertura política dos anos 1990 nos ajudaria a pensar por que nossa literatura dedicou-se mais a tematizar os perigos da indeterminação do que a reconstruir narrativas de determinação do sofrimento, pendentes dos anos de supressão e censura.

Tomemos aqui o trabalho de Hal Foster que usou a teoria psicanalítica do trauma ressignificado em dois tempos, pela ação a posteriori (nachträglichkeit), para pensar a relação entre as vanguardas dos anos 1930 e o retorno das vanguardas nos anos 1960. Se é possível pensar um correlato desse processo para o caso brasileiro isso significa que no momento mesmo em que a rediscussão da brasilidade retornava na chave invertida das neovanguardas há uma interrupção do processo. Não obstante quando a elaboração dessa problemática é retomada, nos anos 1990, ela deve ser feita com um ingrediente traumático adicional, a saber, as primeiras intervenções neoliberais na economia, na cultura e nas artes. 
Segundo Foster (2014, p.40), teríamos que pensar o retorno das vanguardas como um processo duplo, que implicaria uma espécie de retorno do recalcado, mas também de um retorno no Real.

Com base no modelo freudiano [da repressão e da repetição], se a vanguarda histórica foi reprimida institucionalmente, ela foi repetida na primeira neovanguarda, e não segundo a distinção freudiana, recordada, e suas contradições trabalhadas. (ibidem)

Certamente o trauma pode ser mobilizado, como Guinzburg (2012) o faz, para pensar as inflexões da literatura brasileira em torno da violência. Mas essa seria também uma violência dupla, descendente de nossos esquemas de determinação diferencial, como a escravidão, o patriarcalismo, a opressão de classe e a misoginia, mas também uma violência de indeterminação, com a entrada gradual de um novo sistema de produção e administração da anomia. A constituição de 1988, que reforçava as obrigações de proteção social do Estado, em concomitância com políticas de privatização e adiamento de reformas que lhe seriam consequentes, como a implantação do Sistema Único de Saúde e Assistência Social, é um bom exemplo como dois processos traumáticos podem acontecer simultaneamente. Se isso é correto, podemos dizer que a produção do mal-estar nos anos 1990, e depois o seu retorno nos anos 2010, é uma curiosa combinação entre narrativas de sofrimento por determinação, que tentam realizar o luto da ditadura passada, com narrativas de sofrimento por indeterminação, que tentam escrever o trauma da implantação neoliberal vindoura.

Além disso, poderíamos qualificar diferentes modos de incidência do traumático em termos narrativos. A intrusão do objeto, a violação do pacto, a alienação da alma ou a dissolução da unidade simbólica de pertencimento são estratégias narrativas de interpretação do trauma e de formação de sintomas. Lembremos que enquanto o sintoma é um retorno do simbólico do que foi inscrito no simbólico, o trauma implica o retorno do real do que não se inscreveu no simbólico.

Se pensarmos essa hipótese para o Brasil veremos que a neovanguarda dos anos 1960 foi brutalmente suspensa por meio de um acontecimento traumático: o golpe civil-militar de 1964. Portanto, temos aqui a exata circunstância na qual temos que pensar ao mesmo tempo o retorno sintomático no simbólico e sua continuidade no real. No primeiro caso o luto é suspenso e a perda é negada simbolicamente e incorporada, modificando o sujeito. No segundo caso o luto não é iniciado, o acontecimento traumático não é reconhecido, e nesse caso o sujeito se apaga como tal.

Nos dias em que meu pai esteve preso, apanhando e recebendo choques no pau de arara, algo nele se perdeu. Nos 28 anos seguintes ele viveu, a identidade insistia que se tratava do mesmo Milton Luiz Belliantani de quem herdei o nome. Mas o pai que sobreviveu ao inferno da rua Tutóia com Tomás Carvalhal, no bairro do Paraíso, nunca mais foi o mesmo dos meus 14 anos. (Ocariz, 2015, p.343) 
O trauma cria assim uma determinação por descontinuidade, que torna marcados não só os que por ele passaram, mas a todos os quais ele se transmite, literária ou experiencialmente. Por outro lado, o trauma cria uma indeterminação sobre o que exatamente se perdeu, quais são os meios de retomada e de apropriação. O trauma comporta, assim, uma vertente de verdade, e outra de real.

Muitas pessoas associam a psicanálise, e a época em que ela surgiu, com o grande tema da sexualidade suprimida, a um tempo de verdade mais íntima e negada no sujeito e a prática mais real de sua despossessão. Foucault mostrou que as coisas podem não ser bem assim. O século XIX organizou-se em torno da hipótese repressiva muito antes de Freud. Localizar nossa verdade no sexo pode ter implicações discursivas para nossas práticas desejantes e essas podem ir além da mera revelação da verdade sexual. Contudo, essa é apenas uma face do problema. A segunda parte das teses freudianas, muito mais esquecida, afirma que nós somos extremamente intolerantes e repressivos com relação à nossa própria violência. $\mathrm{O}$ mau-trato da violência torna suas manifestações mais erráticas e mais ofensivas ao laço social. Lembremos. Em Édipo não se trata apenas de sentimentos licenciosos com a mãe, mas de hostilidade, e muitas vezes de hostilidade misturada com erotismo. O casamento mórbido entre o sadismo do supereu e o masoquismo do eu, seja ele intrasubjetivo, seja ele intersubjetivo, é um grande tema literário desde as neovanguardas dos anos 1960 até a literatura contemporânea na qual a violência adquire um valor onipresente conforme a demonstração vigorosa de Jaime Guinsburg (2012). Se há um passo a dar a partir da psicanálise para a literatura, e mais especificamente para a crítica da opressão e da desigualdade, esse consiste em repensar as condições heterogêneas de produção e reprodução da violência.

A violência, como nome que articula o mal-estar, entre a experiência da perda e a perda da experiência, é um ponto de partida comum para a literatura e o cinema nesse período, contudo pelas próprias características da linguagem fílmica, notadamente sua propensão para a ação. Enquanto o cinema investiu em novas narrativas de sofrimento a literatura, assim como as artes plásticas parecem ter se concentrado na exploração da resistência de nomeação, que caracteriza o mal-estar.

\section{A violência como nome pluriunívoco do mal-estar}

Segundo Jaime Guinsburg (2012, p.59), a violência é uma espécie de ponto de convergência privilegiado para entender esse período.

O testemunho é necessário em contextos políticos e sociais em que a violência histórica foi muito forte, desempenhando papel decisivo na constituição das instituições. Nesses contextos, as diferenças de perspectiva entre os setores em conflito implicam diferenças formais e temáticas nas concepções de escrita e em recursos institucionais de legitimação" (Ginzburg, 2012, p.59) 
A partir dos anos 1980, e de forma mais consistente nos anos 1990, o Brasil parece ter descoberto a violência como significante que o representa. Com isso ela passa a correr o risco permanente de estetização, por meio da qual ela é transformada, portanto, em "teleshow" da realidade, que pode ser consumido com extremo prazer, mostrando-se randômica, destituída de sentido e chegando à pura espetacularidade. Ivana Bentes $(2007$, p.250) já apontou como se tratava de criar uma ética e uma estética para imagens de dor e revolta sem, contudo, "estetizar" a dor, a miséria e a violência. A violência separa-se da determinação ética, afastando-se também do ambiente social de onde ela nasce. Para fazer isso, é preciso entender que o contexto passa a ter outra função que não a de caracterizar personagens.

A violência se banaliza como cenário e surgem histórias que são entregues ao espectador de forma naturalista, com materiais reais e baseados nas regras da verossimilhança para a composição da imagem - o que pode apresentar efeito pernicioso sobre a representação, pois é como se cenas carregadas de "autenticidade pornográfica" e "violência sensorial" ocorressem a todo instante, em toda esquina das cidades brasileiras. Como se os habitantes de periferias e favelas fossem naturalmente violentos e como se o olhar do leitor demandasse violência; aliás, fato social notável a partir da ascensão, nesse período, dos programas televisivos "catárticos" em torno do tema. Mas justamente se trataria de mostrar como nem toda catarse é apenas vivência indireta de uma fantasia de vingança, que incremente o medo e a dependência em vez de criar as verdadeiras condições para uma catarse capaz de desintegrar as narrativas das quais depende e re-nomear o mal-estar da qual emerge.

Entre 2000 e 2013 há um processo de segmentação e de nomeação da incidência diferencial da violência. A seletividade da violência contra negros, mulheres e minorias vulneráveis torna-se um problema reconhecido e institucionalmente tratado. Surgem as política específicas para o sofrimento de gênero, os dispositivos de inclusão, os sistemas de cotas. A literatura torna-se sensível ao sofrimento em sua valência política deslocando sua gramática da antiga oposição entre a família e o trabalho, da vida privada e da vida pública para litorais indeterminados de tensão e de conflito. Nesse sentido ela trabalhou ativamente para criar dispositivos de reconhecimento para essa nova situação, em meio à substituição da culpa pela vergonha como afeto social dominante.

\section{Intrusão de objeto}

A violência derivada do trauma, que retorna sob forma de repetição, errática ou silenciosa, assoreando o laço social por meio do ressentimento indiscernível, possui íntima relação com nosso hiato histórico representado pelo regime de exceção, que instituiu um modo de funcionamento baseado na violência de Estado. Essa narrativa, que está renascendo no atual momento, está baseada na suposição de existência de um grupo social que precisa ser reduzido ou eliminado para que a "harmonia" se restabeleça. Um exemplo atual que sobrevive 
em nossa conivência com o extermínio de jovens negros na periferia das grandes cidades, como o grupo de Eu sou favela (Carrascoza et al., 2013) conseguiu dar expressão testemunhal.

Pertence à mesma linhagem o trabalho de Veronica Stieger (2010, p.4552) no conto "Curta-metragem" que descreve, em linguagem de roteiro cinematográfico, um casal que contempla o vazio da sacada de seu prédio. Quando a mulher vai reduzir o volume da televisão o marido se atira. Ela se dá conta do ocorrido e pula atrás caindo sobre seu corpo. Ela luta no asfalto para tocar sua mão na dele. Segue-se o diálogo daqueles que teriam muito pouco e, portanto, decisivamente algo a dizer, um ao outro: "Acho que você quebrou alguma coisa [...] Desculpe, não era minha intenção". Acho que seus óculos ficaram nas minhas costas. Eram caros os óculos. "Você conhece o mito do fusca?" Um fusca vem sempre acompanhado de outro. Depois de um fusca sempre vem outro. $\mathrm{O}$ diálogo aparentemente vazio sucede um instante de insânia, sem nenhum sentido antecipável. Ali onde o leitor espera um significante mestre que retorne sobre o ocorrido, o que temos é uma fala vazia. A contingência do sofrimento exemplifica a lógica narrativa do mal-estar como ponto de cruzamento entre determinação de uma causa e indeterminação de sua nomeação: "você quebrou algo em mim, quiçá na minha alma. Ainda que não fosse sua intenção, você deixou algo encravado em minhas costas, talvez uma faca? E em desespero você salta pela janela, como outro fusca eu te seguirei, sem motivo e sem necessidade". Ocorre que essa narrativa está em elipse, e mesmo assim o seu centro sugerido está na ausência de sentido da vida de um casal assistindo televisão. Operação que Lacan chamou de ab-sense, ou de sens-blanc, ou seja, de extração do não sentido na perturbadora presença da letra para além do significante.

Se recuarmos a procura do tema do objeto infiltrado como indício de que uma experiência se desfez encontraremos na produção de Caio Fernando Abreu a mesma combinação insólita entre a falta de sentido e a irrupção de um objeto improvável. Em Sargento Garcia, de 1982 (Abreu, 2015), um jovem se apresenta para o serviço militar e é maltratado pelo selecionador. Depois de humilhado, excluído e rebaixado porque não se apresentava com os traços viris para entrar no grupo militar, a virada do conto mostra o mesmo sargento dando-lhe uma carona e entregando-se ao encontro sexual com o mesmo objeto intrusivo que ele antes queria expulsar.

Talvez o exemplo mais bem acabado do trabalho de elaboração da intrusão do objeto com o abismo que ele traz consigo, com a gradual passagem da determinação para a indeterminação, pode ser encontrado em O filho eterno de Cristóvão Tezza. Um texto que descreve o impacto da descoberta de um diagnóstico que torna aquele que até então era o mais íntimo depositário das esperanças de uma família o externo representante de um fracasso. A violação de todas as expectativas torna esse ser um estranho preso em seu próprio tempo e incomensurável com nossos sonhos: 
Em um átimo de segundo, em meio à maior vertigem de sua existência, a rigor a única que ele não teve tempo (e durante a vida inteira não terá) de domesticar numa representação literária, apreendeu a intensidade da expressão "para sempre" - a ideia de que algumas coisas são de fato irremediáveis, o sentimento absoluto, mas óbvio, de que o tempo não tem retorno, algo que ele sempre se recusava a aceitar. (Tezza, 2007, p. 30)

\section{Violação do pacto}

Ela se combina com a violência que a precedeu e de certa maneira a tornou possível, e que provém da relação de instrumentalização da lei no contexto da colonização e da escravidão. Aqui a narrativa de sofrimento é outra. Trata-se do pacto mal feito, da lei que não se produz pela concorrência e concordância daqueles que a ela se submetem. Trata-se de nossa desconfiança com o pacto que é apenas mimeticamente liberal e republicano. O caso mais patente aqui é o descaso com miseráveis e pobres que durante muito tempo permaneceram à margem a lei e da cidadania. Quero crer que a ascensão dos chamados romances históricos na literatura e um novo interesse pelos limites entre ficção e documentário, no cinema, têm uma grande relação com a investigação desse pacto social e suas sucessivas traições, vinganças e degradações. No centro dessa problemática está a figura do pai obsceno que se identifica como exceção à lei que cria a lei. É o tipo de violência que depende de uma desfusão das pulsões, como falava Freud, ou uma entropia de gozo, segundo Lacan. É uma violência que retorna como por meio de uma falsa unificação superegoica: o pai da horda, o pai da ordem, o pai celestial.

É o que se pode ver em Rútilo Nada de Hilda Hilst (1993). Esse conto disposto em duas perspectivas, primeiro a de Lucius e depois a de Lucas, culmina em uma "fusão de perspectivas" (Viveiros de Castro, 2014, p.293). ${ }^{1}$ O pai de Lucius, inconformado com o romance de seu filho com Lucas, contrata capangas para matá-lo. Na cena final desfere um enigmático beijo no amante do filho, que em resposta se mata. A moral estrutural é simples: o pai "rouba" Lucas de Lucius assim como o filho tinha roubado Lucas de sua própria filha. É o tema do pai que deixa irromper seus interesses libidinais contra a preservação da relação de filiação, análogo sem dúvida a Copo de cólera ou Lavoura arcaica de Raduan Nassar (1975). Nessa pequena tragédia o mal-estar com a lei é formalmente elaborado com as inúmeras alusões ao animal (escorpião) como negação tanto do amor quanto da morte. A anarquia de gêneros que o conto promove se desdobra em uma precariedade da "ocupação do lugar do narrador", 2 sua “intermitência” e em uma “dissociação ou divisão do sujeito" (Souza, 2016). Por outro lado, há uma identificação preservada, pois "quando morre o eu do poeta, a pessoa morre”. Ou seja, a morte acaba sendo o tema por meio do qual o narrador curiosamente retém sua identificação.

O procedimento de sutura do narrador pode ser localizado nos personagens secundários, por exemplo, o pai impostor em Rútilo Nada. Assume espe- 
cial centralidade na leitura do romance o seu desfecho em suicídio. Acompanho sua hipótese de que se trata de um autossacrifício, mas no fundo a indeterminação começa e não termina aí. Afinal há várias maneiras de se sacrificar, e segundo Viveiros de Castro há duas maneiras bem diferentes quer privilegiemos o totemismo, quer o animismo perspectivista. O sacrifício totemista, descrito por Freud em Totem e tabu, institui o pai em seu lugar, como pai morto, ato mítico originário do pacto civilizacional. Aliás, o pai morto não é o pai que rouba o namorado da filha, ou que rouba o namorado do filho. Esse é o que Lacan chama de pai real, a face obscena e perversa da lei. Esse é o pai além do muro. Por isso a parte mediana do conto é ocupada por um longo poema:

Muros escuros, tímidos.

Muros longínquos.

Muros como te amei.

Muros de chegança. De querença.

Teu muro de criança.

Muros dilatados de doçura.

Muros do encantado da luxúria.

Muros prisioneiros de seu próprio murar.

Campos da morte. Muros de medo.

Muros silvestres, de ramagens e ninhos

Os meus muros da infância. Esfacelados.

Muros de água. Escuros. Tua Palavra.

Muros intensos.

E outros vazios como furos.

Muros enfermos.

Repensando muros.

(Hilst, 1993, p.26)

Ocorre que segundo a lógica do totemismo o suicídio pode ser lido como uma vingança masoquista. Isso representa um suicídio completamente distinto do suicídio animista, por meio do qual me fundo com a perspectiva inversa de meu matador guerreiro. O suicídio animista não é masoquista ou sádico, mas é um momento de indeterminação do processo de luto, uma identificação não melancólica com o objeto perdido. Aqui não caberia falar em uma mensagem punitiva para o Outro, mas em uma espécie de travessia ao oposto ou então de empobrecimento total. Para avançar nesse ponto faltou a noção de narcisismo. Sem ela fica difícil pensar essa gramática do um e do múltiplo, do si e do outro e essa relação de "indistinção entre os amantes" (Souza, 2006).

O correlato da narrativa sobre a paradoxalidade da lei, em sua conexão intrínseca com a produção da violência que ela pretende erradicar se encontrará 
nos anos 2000 na prosa-poética de Alberto Pucheu (2013). Em seu “Arranjo para tornar o mundo cada dia pior e mais violento" ele transcreve a fala de Wellington Oliveira que em 7 de abril de 2001 invade a escola onde ele havia estudado e em busca de vingança assassina 12 crianças. Em "Arranjo para tornar mundo cada dia menos violento" ele transcreve o nome dos 77 mortos por Anders Breivik na Noruega, e em "Arranjo para tornar o mundo cada dia pior e mais violento, II" ele transcreve o discurso do coronel Eir Costa Filho, da cúpula da segurança do Rio de Janeiro acusando a Secretaria de Direitos Humanos, a $\mathrm{OAB}$ e a Anistia Internacional pelo aumento da criminalidade naquele estado. Tais intercessões discursivas criam contrastes agudos com a experiência íntima da imersão no surf ou nos encontros insólitos do cotidiano. Assim como em Hilst, o contraste é resolvido por meio de uma espécie de objetalização do corpo, a carne do humano em forma de objeto:

Suas vísceras são feitas de cama. Os pulmões, de madeira. A coluna de uma ripa do estrado. A intimidade das cabeceiras encontro em seus braços. $\mathrm{O}$ peito é, certo, um colchão [...] E onde todos os outros colchões são fabricados. O intestino as molas e mais molas. (Hilst, 1993, p.92)

\section{Alienação}

Há uma terceira forma de mal-estar, menos ostensiva, mas talvez mais perniciosa e que envolve rituais de humilhação, segregação e inveja que ricos impõem aos mais pobres. Foi o que tentei tornar mais visível com a tese da vida em forma de condomínio. A invisibilidade do "outro perigoso" gerida pelo muro de exclusão e de recusa de reconhecimento, baseada na retórica securitária da segurança, terminou por elevar o medo à condição de afeto central da política. Ela aparece, por exemplo, na figura do estrangeiro e do estranhamento, como vemos na prosa de Bernardo Carvalho (2009), com seus narradores perspectivistas, como O filho da mãe, ou nas produções de Nuno Ramos que dão continuidade a essa estratégia, em sua autópsia da matéria, a mesma busca do terceiro elemento real, entre o corpo e a linguagem.

O sofrimento dos outros não há mais, aquele degrau onde tropeço, o peda-

ço de música que não esqueço. (Ramos, 2001, p.79)

O tema do excesso da lei ganha agora outras modalizações, pois não se trata apenas de criticar as figuras que encarnam seu paradoxo ou seu excesso, mas de apontar para nossa complacência e tolerância ou para a voz cuja enunciação nos torna partícipes da violência como na Instalação 111, de 1992, que narra, por meio da enunciação dos nomes, o assassinato dos presidiários do Carandiru.

Um exemplo mais narrativo ainda desse procedimento se encontrará em Destino Sé de Simone Paulino (2010, p.67-83), que aborda a mesma insípida, incolor e inodora modorra de sentido, e incomunicabilidade de experiência em uma menina de nove anos que vive em uma favela da grande São Paulo. Indo para a escola ela descobre um despacho em uma encruzilhada e rouba uma das 
rosas ali depositadas. Culpada e temendo o castigo, ela se livra da flor, mas não de seu perfume. Naquela noite ela tem sua primeira menstruação, em silêncio, envergonhada e silenciosa. É o rádio quem lhe salva da perturbação corporal insignificada: "Mulher é bicho esquisito, todo mês sangra, um sexto sentido maior que a razão". Foge de casa, entrega-se ao traficante ao som dos Beatles. Torna-se prisioneira do novo marido de quem alterna sexo e violência: "quem sofre sempre tem que procurar razão para viver" ou "um nasce para sofrer enquanto outro ri”. Foge novamente, agora para a Praça da Sé. O nome para o mal-estar vem de uma fonte errática, impessoal, indicando não apenas a sua pertinência, mas, sobretudo, sua solidão e a rarefação de palavras compartilhadas.

Um correlato poético dessa experiência de alienação é o trabalho de Ana Rüsche (2016), onde a feminilidade é abordada por meio de suas formas metáforas mais materializantes: a anoréxica que se desintegra em luz, o corpo de boneca inflável, a morte semanal em lençóis alugados, o sexo oral com o Unabomber, o corpo como campo de batalha.

O tema da alienação aparecia fortemente na poesia dos anos 1990, notadamente em Rui Proença e Fabio Weintraub, ganhador do Prêmio Nascente em 1994 com Sistema de Erros:

Por que então nós

Não eraremos

Se o erro é o meio

Por que nascemos?

(...)

Errar de cor

Toda lição

Nos labirintos

Do Coração

(Weintraub, 1994, p.56)

A ideia do descaminho e da errância, que aparecia de forma tônica no rock de Renato Russo, na extemporânea entrada de Chico Buarque na literatura, assim como pela consciência de certo descaminho na conversa sobre a brasilidade. A violência, ainda que próxima e recente, não tinha mais cara nem endereço. A sátira que visara contornar a censura evoluiu para um novo tipo humor, ciente de sua própria alienação. A densidade dos personagens dá lugar à teatralização e ao exagero. A confusão entre a vivência e a factualidade concorre para o hibridismo de gêneros. Gestava-se assim uma série narrativa baseada na função produtiva do estranhamento e da desequilibração calculada de identidades. Pode-se dizer que o tema da alienação sofre uma espécie de colapso e esgotamento com a entrada brutal da experiência digital e com a descoberta de um conjunto variado e insuspeito de formas de demitir-se da implicação a si. 


\section{Dissolução de unidade simbólica}

O texto de 1982 A teus pés, de Ana Cristina César (2016, p.15), pode ser lido como a construção de um grande naufrágio. Nessa reedição aquática da terra em transe, a poesia e a prosa trabalham entre dois grandes humores: a depressão e a inquietude. A perda, iminente e pressentida, aparece na tese de que a "subjetividade se parece com um roubo inicial", no "tesão do talvez", nas "ciganas do horário nobre". O jogo entre a linguagem mais elaborada e cotidiana do provérbio popular com a elaboração formal leva a fórmulas inesquecíveis como "As mulheres e as crianças são as primeiras que desistem de afundar navios" (ibidem, p.20). Ou então no poema Cartilha da cura:

A poesia não - telegráfica - ocasional

Me deixa sola - solta-

À mercê do impossível -

do real. (ibidem, p.32)

Há vários nomes para o mal-estar em Ana C.: "angústia da felicidade" (ibidem, p.36), "divisão do coro em heterônimos" (ibidem, p.65), "não sinto nada" (ibidem, p.66) "coceira no hímen" (ibidem, p.70), "cansaço de ser homem" (ibidem, p.76).

Uma boa contrapartida ao sofrimento de indeterminação dos anos 1980, que caracteriza a prosa de Ana Cristina César e a poesia de Armando Freitas Filho, pode ser encontrada nos trabalhos de João Paulo Cuenca como $O$ único final feliz para uma história de amor é um acidente (2010) ou Descobri que estava morto (2016). Outro autor que parece tematizar formalmente a dissolução da unidade é João Carrascoza (2014), em seu Caderno de um ausente, no qual parte decisivas de seu conto são marcadas por uma borrão branco deixando a leitura sistematicamente incompleta e indeterminada quanto ao sentido.

$\mathrm{Na}$ literatura informada pela psicanálise vemos emergir uma continuidade recente dessa série ligada à análise das experiências de dissolução, como a loucura da mãe em Isloany Machado (2017), a perda do filho em Bia Dias (2017), a desagregação da experiência do tempo em Wesley Peres (2013) e o próprio percurso de uma análise em Luciana Salum (2016). Isso denota um giro no foco de preocupação literária e clínica dos psicanalistas, da forma romance, na qual Freud estabeleceu suas intelecções, para a pesquisa sobre narrativas que possam incluir a indeterminação tanto do ponto de vista formal e construtivo quanto do ponto de vista temático e do tratamento da contradição social.

O que não pode ser dito, o fracasso do dizer, o fato de que há uma dificuldade inerente da linguagem para traduzir algo insiste na literatura brasileira que pesquisa os limites entre a impossibilidade estrutural e o que recobre esta impossibilidade com uma impotência criativa ou social. 


\section{Conclusão}

Trauma como a violência do excesso, Édipo como o problema da lei hiperpessoalizada, o narcisismo como bloqueio de experiências de reconhecimento e o supereu como angústia e gozo na felicidade precisam ser pensados de forma "intersecional" se queremos incluir as atuais reflexões literárias em uma política mais universalista sobre o mal-estar. Veronica Stieger, Hilda Hilst, Simone Paulino e Ana Cristina César parecem trabalhar sobre uma linha de base que é a violência. A violência do suicídio, a violência do estupro, a violência do aprisionamento feminino situam-se como casos de sofrimento de determinação, ao passo que a violência do naufrágio da experiência é um exemplo de uma nomeação indeterminativa do mal-estar. Ainda que estejamos em momentos muito distintos podemos agrupar essa série em dois grupos: Ana Cristina César, em 1982, e Verônica Stieger, em 2010, compõem uma série baseada no sofrimento como excesso de experiências improdutivas de indeterminação. Hilda Hilst, em 1993, e Simone Paulino, em 2010, são casos da série que narrativiza o sofrimento em termos de déficit de experiências produtivas de indeterminação. Nas duas séries podemos verificar a persistência da nomeação do mal-estar como violência. A diferença reside principalmente na tematização formal do esvaziamento de sentido, presente nas duas primeiras autoras e ausente nas duas últimas. $\mathrm{Ou}$ seja, se em 1993, em plena Retomada, tratava-se ainda de determinar os efeitos do período de violência civil militar, de fazer a memória ou de retornar ao que havia sido perdido, em 2010, às vésperas de uma nova interrupção da história democrática do país, o problema evolui para uma espécie de retorno do real, do que não pode ser inscrito no processo de luto.

São duas incidências narrativas distintas do pai. Em 1993 ele é convocado como posição narrativa fundamental para organizar, justificar ou criticar o excesso da violência. Contrastivamente, em 2010, o pai parece uma figura dispensável, ele não está em falta nem em excesso, ele não é efígie da autoridade nem obscenidade do poder. Em seu lugar surge o masculino como princípio generalizado do mal-estar.

Uma figura que faz metáfora para o sintoma nos anos 1990 é o muro. A persistência de uma estrutura espacial, que comprime e sutura o tratamento do conflito, que torna invisível a diferença. Para a narrativa feminina dos anos 2010 o plano sintomático está organizado pelo ato, o ato de sair da favela, rumo à praça da Sé, o ato de lançar-se pela janela do edifício em desespero mimético ao amor sem palavras. $\mathrm{O}$ que se orienta para a insurgência e reviramento da autoridade, familiar no primeiro caso, aparece como ato errático e imprevisível no segundo subgrupo.

Mas se a linha de base do mal-estar é formada pela nomeação do mal-estar como violência, compondo assim uma série narrativa, a segunda série narrativa componente da garrafa de Klein à brasileira, instancia a violência em modalidades de inversão. A intrusão do objeto está para o excesso da lei assim como a alienação da alma está para a dissolução da unidade simbólica do espírito. 
A narrativa da intrusão do objeto argumenta que o mal-estar advém das propriedades misteriosas e desorganizativas trazidas pela diferença de gozo: a homossexualidade, as drogas, a dependência consumista, os migrantes, os pobres, os que estão fora de lugar, os que estão a mais nas cadeias, nas favelas, nas periferias das grandes cidades. Ela pede por uma torção narrativa que aparece nos muros, nos condomínios, no extermínio de presidiários do Carandiru, no pai que manda matar o amante de seu filho. Oscilamos então entre uma superfície de uma banda de Moebius que lê na realidade um déficit de lei e que impõe uma recontratualização permanente desse déficit, como aumento da força da lei e o retorno, na outra superfície dessa mesma banda, do que é excluído pela aplicação dos muros, o retorno do que é negado a ser incluído nos processo de sua institucionalização precária e seletiva. A indeterminação trazida pelo objeto intrusivo é perpetuamente compensada pela convocação da determinação representada pela lei e pelo novo pacto por vir. Estamos entre o Vampiro que nos parasita e o Fantasma de uma lei que nos salvaria desse excesso por meio de um excesso que se revela ainda mais violento.

Por outro lado, podemos descrever uma segunda Banda de Moebius formada por duas séries narrativas. Na superfície cis dessa banda encontramos a narrativa da alienação da alma, com seus pequenos romances de formação, na qual se descobre a condição feminina, a negritude, a pobreza como experiência determinativa ainda que reconhecida com atraso. Na superfície trans da banda de Moebius encontramos a razão que indetermina o fracasso sistemático de reconhecimento. A alma não pode se reencontrar porque a linguagem que teria sido necessária para isso se perdeu, não está mais acessível ou ainda não foi inventada. Ali onde é possível nomear o desejo o sujeito está ausente, e ali onde ele aparece como sujeito não há mais desejo possível ou viável. Estamos entre o Zumbi que trabalha sem pensar e o Frankenstein que consegue pensar, mas ao preço de perder seu sentimento de pertença simbólica.

Os anos 1993 e 2010 são ainda datas anteriores a 2013, momento no qual esse sistema que interliga a estabiliza narrativas de sofrimento, modalidades de sintomas e funções de nomeação do mal-estar parece ter chegado a seu esgotamento. O ajuste de contas mal feito com os excessos da violência dos tempos de ditadura engendrou uma moral da retomada no cinema e uma ética da reconquista na literatura. O seu sintoma inicial é a ruptura da linha de Jordan que costurava as duas bandas de Moebius em uma mesma linha de base. A retórica da violência desloca o objeto intrusivo para "esquerdopatas", "corruptos" e "traidores" enquanto a "nova lei" reformista perde sua conexão com a contenção e articulação de diferenças. Por outro lado, a narrativa da alienação reaparece como desligamento institucional autorizando processos de desmonte premeditado das unidades simbólicas ligadas à infância e à velhice, aos que dependem da assistência social ou dos recursos de proteção social em saúde ou educação. Tudo se passa como se agora a produção de leis se orientasse para a dissolução de unidades simbólicas e o objeto intrusivo dependesse cada vez mais da alienação ao ódio. 
Notas

l “A relação é criada precisamente pela supressão de um de seus termos, que é introjetado pelo outro; a dependência recíproca que liga e constitui os sujeitos da troca atinge aqui o ponto de fusão - a fusão dos pontos de vista - onde a distância extensiva e extrínseca entre as duas partes converte-se em diferença intensiva, imanente a uma singularidade dividida. A relação de predação constitui-se em modo de subjetivação".

2 "Não se pode mais narrar, embora a forma do romance exige narração" (Adorno, T. Posição do narrador no romance contemporâneo. In: Notas de Literatura I).

\section{Referências}

ABREU, C. F. Morangos mofados. Rio de Janeiro: Nova Fronteira, 2015.

BENTES, I. Sertões e favelas no cinema brasileiro contemporâneo: estética e cosmética da fome. $A L C E U$ - v.8, n.15, p.242-255, jul./dez. 2007.

CARRASCOZA, J. A. et al. Eu sou favela. São Paulo: Nós, 2013.

Caderno de um ausente. São Paulo: Cossac Naify, 2014.

CARVAlHO, B. O filho da mãe. São Paulo: Cia. das Letras, 2009.

CÉSAR, A. C. A teus pés. São Paulo: Schwarcz, 2016.

DEleuZE, G.; GUATARRI, F. Kafka, Por uma Literatura Menor. Belo Horizonte: Autêntica, 2014.

DIAS, B. Névoa e Assobio. Rio de Janeiro: Relicário, 2015.

DUNKER, C. I. L. Estrutura e constituição da clínica psicanalitica. São Paulo: Annablume, 2012 .

. Mal-estar, sofrimento e sintoma: uma psicopatologia do Brasil entre muros. São Paulo: Boitempo, 2015.

DUNKER, C. I. L.; PAULON, C.; MILAN-RAMOS, G. Análise psicanalitica de discurso: perspectivas lacanianas. São Paulo: Estação Letras e Cores, 2016.

DUNKER, C. I. L.; RAVANELLO. Gênero e forma literária: considerações sobre a estrutura ficcional dos casos clínicos em psicanálise. Cad. Psicanál. (CPRJ), Rio de Janeiro, v.39, n.36, p.87-102, jan./jun. 2017.

FOSTER, H. O retorno do real. São Paulo: Cosac Naify, 2014.

GINZBURG, J. Literatura, violência e melancolia. Campinas: Autores Associados, 2012.

HILST, H. Rútilo Nada. Campinas: Pontes, 1993.

LACAN, J. Séminaire livre IV: La relation de objet. Paris: Seuil, 1955.

MACHADO, I. Nau dos Amoucos. Porto Alegre: Metamorfose, 2017.

NASSAR, R. Lavoura arcaica. Rio de Janeiro: José Olímpio, 1975.

PAULINO, S. Destino Sé. São Paulo: Scipione, 2010.

OCARIZ, M. C. Violência de Estado na Ditadura Civil-Militar Brasileira (1964-1985).

Efeitos psíquicos e testemunhos clínicos. São Paulo: Escuta, 2015. 
PERES, W. Pequenas Mortes. Rio de Janeiro: Rocco, 2013.

PUCHEU, A. Mais cotidiano que o cotidiano. Rio de Janeiro: Azougue, 2013.

RAMOS, N. O pão do corvo. São Paulo: 34, 2001.

RÜSCHE, A. Furiosa. São Paulo: Rüsche, 2016.

SALUM, L. K. Fragmentos: o que se escreve de uma psicanálise. São Paulo: Iluminuras, 2016.

SOUZA, J. Mais além dos muros: o amor, a morte e os limites do humano em Rútilo nada de Hilda Hist. 2016. Dissertação (Mestrado em Literatura Brasileira) - Faculdade de Filosofia, Letras e Ciências Humanas, Universidade de São Paulo. São Paulo, 2016.

STIEGER; V. Curta-metragem. São Paulo: Scipione, 2010.

TEZZA, C. O filho eterno. Rio de Janeiro: Record, 2007.

VIVEIROS DE CASTRO, E. Metafísicas canibais. São Paulo: Cosac Naiffy, 2014

WEINTRAUB, F. Sistema de Erros. São Paulo: Arte Pau Brasil, 1994.

ZULAR, R. Luto, antropofagia e a comunidade como dissenso. In: PENNA, J. C.; DIAS, A. (Org.) Comunidades sem fim. Rio de Janeiro: Circuito, 2014.

RESUMO - Examina-se comparativamente a literatura brasileira dos anos $1990 \mathrm{com}$ os anos 2010, tendo em vista a maneira como esta distribui suas narrativas de sofrimento. Tomam-se tais narrativas segundo o grupo das que denotam sofrimento por excesso de experiências produtivas de determinação ou por falta de experiências produtivas de indeterminação, traduzindo assim a dialética entre a verdade e o real segundo as teses da psicanálise de J. Lacan. Propõe-se um modelo sobre as séries transformativas em curso, tendo em vista os destinos do traumático ligado à ditadura civil-militar e o retorno da violência social nos anos 2010.

PALAVRAS-CHAVE: Mal-estar, Sofrimento, Sintoma, Literatura, Psicanálise

ABSTRACT -We comparatively analyze Brazilian literature in the 1990s and in the 2010s, stressing the ways we can distinguish their narratives of suffering. We arrange these narratives in two groups: suffering through an excess of unproductive experiences of determination and suffering through a lack of productive experiences of indetermination, thus translating the dialectics between truth and reality from Lacanian psychoanalysis. We propose a model based on transformative series, taking into account the destinies of trauma associated with the military-civil dictatorship and the return of social violence in the 2010s.

KEYWORDS: Malaise, Suffering, Symptom, Literature, Psychoanalysis.

Christian Ingo Lenz Dunker, psicanalista, é professor titular do Instituto de Psicologia da USP. @ - chrisdunker@usp.br

Recebido em 15.9.2017 e aceito em 9.10.2017.

I Instituto de Psicologia, Universidade de São Paulo, São Paulo, Brasil. 